\title{
Detection of Human Papilloma Virus in Oral Potentially Malignant Disorders and Oral Squamous Cell Carcinoma
}

\author{
Snehashish Ghosh, ${ }^{1}$ Sartaj Singh Wazir, ${ }^{2}$ Rajesh Shah, ${ }^{3}$ Manoj Kumar Upadhyay, ${ }^{4}$ Rahul Gupta, ${ }^{5}$ Harendra \\ Mohan Singh ${ }^{6}$ \\ 'Department of Oral Pathology, ${ }^{2}$ Departmentof Oral Medicine \& Radiology, ${ }^{3}$ Department of Periodontics, ${ }^{4}$ Department of \\ Conservative Dentistry and Endodontics, ${ }^{5}$ Department of Prosthodontics, ${ }^{6}$ Department of Conservative Dentistry and Endodontics, \\ M. B. Kedia Dental College, Birguni, Nepal.
}

\begin{abstract}
Introduction

Human Papilloma Virus (HPV) 16 and 18 affects the keratinocytes of oral mucosa and skin and can lead to the development of dysplastic lesions and ultimately into invasive oral squamous cell carcinoma. The objective of the present study was to evaluate the presence of human Papilloma virus 16 and 18 DNA in already diagnosed oral potentially malignant disorders and oral squamous cell carcinoma.
\end{abstract}

\section{Methods:}

200 biopsy specimens (50 each) of already diagnosed leukoplakia, oral lichen planus (OLP), oral submucous fibrosis (OSMF) and oral squamous cell carcinoma was included for the study. A total 50 control tissue sections, which were obtained during removal of impacted teeth were also included in the study. All 250 specimens were subjected to polymerase chain reaction (PCR) for the identification of HPV 16 and 18. The results are analyzed using Statistical Package of Social Sciences (SPSS) version 16 software and Pearson's chi square test was used for statistical analysis.

\section{Results}

HPV 16 and 18 was noted in all the OPMDS and oral cancer specimens but the results were not statistically significant. However, not even a single case of control tissue showed the presence of HPV 16 and 18.

\section{Conclusions}

The results of the present study shows HPV 16 and 18 is present in oral cancer as well as OPMDS, therefore it could be implicated in the pathogenesis of the above mentioned conditions.

Keywords: HPV; OPMDS; oral cancer; pathogenesis.

Correspondence: Dr. Snehashish Ghosh, Department of Oral Pathology, M. B. Kedia Dental College and Teaching Hospital, Birguni, Nepal. Email: ghoshrocks2004@gmail.com. Phone: +977-9811885204. 


\section{INTRODUCTION}

Oral squamous cell carcinoma (OSCC) is one of the most common head and neck malignancy, with more than 2 lakh new cases are recorded every year. $^{1}$ OSCC is often preceded by various oral potentially malignant disorders (OPMDS) most commonly leukoplakia, oral lichen planus, oral submucous fibrosis (OSMF). Various etiological factors, most commonly different forms of tobacco, alcohol, chronic irritation, candidal infection has been well known for the development of OPMD and OSCC. 1,2,3Proliferative Verrucous Leukoplakia, a multifocal form of leukoplakia with increased risk for transformation into malignancy ${ }^{4}$ can also be associated with HPV. ${ }^{5}$

Human Papilloma virus (HPV) has also been attributed in the pathogenesis of OPMD and OSCC. The percentage of HPV associated OSCC is only $2.2 \%$, but association of HPV in oropharyngeal lesions is nearly $30.8 \% .^{5}$ The exact connection between HPV and OPMD and OSCC is still under the cover. Many scientists have mentioned about the geographical differences in the occurrence of HPV associated oral mucosal lesions, which again was affected by the ethnicity, mode of case selection, sampling and detection techniques. Amomg the different strains, HPV16 and HPV-18 are commonly associated with oral and oropharyngeal lesions. ${ }^{6,7}$

Out of the various OPMD, we have included leukoplakia, OLP and OSMF in our study. Epithelial Dysplasia, a distinct clinicpathological entity, commonly seen in the populations with the habit of consumption of tobacco. The percentage of HPV-DNA in the epithelial dysplasia ranges between $6-27.1 \%$. ${ }^{1,8,9}$ OLP is a T-cell related mucocutaneous lesion ${ }^{10}$, affecting near about $1 \%$ of the population. ${ }^{1,11}$ The exact etiology of OLP remain unkown. ${ }^{1,11}$ Various authors in their studies have stated the presence of HPV 16 and 18 in OLP12,13, whereas many authors have denied it also. ${ }^{14,15}$ OSMF, a collagen disorder commonly seen in the individuals with the habit of chewing arecanut. ${ }^{16}$ Not much studies are documented on the association of HPV and OSMF.

The present study aims to evaluate and compare the presence of HPV16 and 18 in already diagnosed OPMDS like epithelial dysplasia, OLP, OSMF and oral squamous cell carcinoma (OSCC).

\section{METHODS}

The present study was conducted from the routine biopsy specimens of the department of oral pathology, M. B. Kedia Dental College Pvt. Ltd, Birgunj, Nepal. Ethical clearance for the study was obtained from the institutional review board of the above mentioned institution (45/MBKDC/ ADV/06/2018). The study was conducted from 01August 2018 to 31 December 2019.

A total of 150 cases (50 each) of already diagnosed cases of OPMD's including epithelial dysplasia, OLP, OSMF and 50 cases of OSCC between August 2018 and September 2019 were included in the study. Total 50 healthy oral mucosal tissues (controls) were also included in the study. The control tissues were obtained during the surgical removal of the impacted teeth. Socio-demographic data of the study samples were obtained from the requisition forms which were collected during the biopsy.

Thepatientswithoutanyhistoryofchemotherapy, radiotherapy and surgical treatment were included in the study. The patients with the history of any systemic disease like diabetes mellitus, hypertension and the patients with the history of any form of treatment be its surgical, radiotherapy or chemotherapy were excluded from the study.

The tissue samples were fixed in 10\% neutral buffered formalin and underwent normal processing in decreasing percentage of alcohol, followed by xylene and finally embedded in paraffin wax. The tissue sections were cut 
into 5 microns thickness and were stained with Hematoxylin and Eosin (H \& E) stain to reconfirm the histopathological diagnosis. After confirming the diagnosis, DNA isolation was done from the tissue sections, followed by polymerase chain reaction (PCR) for the analysis of HPV 16 and 18.

\section{DNA isolation}

DNA isolation was performed from the formalin fixed paraffin embedded (FFPE) tissue using commercially available kit QIAamp DNA FFPE tissue kit (QIAGEN). The tissue sections are deparaffinized in xylene, followed by clearing in varying grades of alcohol. Then the tissues are dried at room temperature followed by treatment in proteinase $\mathrm{K}$ and incubated at $56^{\circ}$ $\mathrm{C}$ for 1 hour, followed by overnight incubation at room temperature, for the complete lysis of the tissue. On the following day, the lysed tissue was incubated at $90^{\circ} \mathrm{C}$ for 1 hour, thereby DNA extraction was done using elute column and buffers supplied with the kit. Quality of the DNA extracted was reviewed by running on 0.8 $\%$ agarose gel. After the evaluation the extracted DNA samples were stored at $-20^{\circ} \mathrm{C}$.

\section{Polymerase Chain Reaction (PCR)}

The extracted DNA from the tissue samples were exposed to PCR. Initially denaturation was done at $95^{\circ} \mathrm{C}$ for 5 minutes followed by 35 cycles of denaturation each for 30 seconds duration. Annealing was done for 30 seconds at $55^{\circ} \mathrm{C}$, followed by extension at $75^{\circ} \mathrm{C}$ for 30 seconds. The final extension was done in 20 microliter of PCR reaction mixture. The PCR reaction mixture was a composite of $50 \mathrm{ng}$ of DNA extracted from the tissue, 15 picomole each of oligonucleotide primer and the reaction product was again evaluated with $0.8 \%$ agarose gel electrophoresis.

The primers used in the PCR

HPV 16 E6 Forward Primer: ACCGGTCGATGTATGTCTTGTTG
HPV 16 E6 Reverse Primer:

GATCAGTTGTCTCTGGTTGCAAATC

HPV 18 E7 Forward Primer: CTATAGAGGCCAGTGCCATT

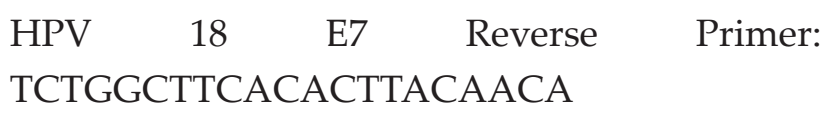

The components used in PCR were 2 microliter each of forward and reverse primer and 10 microliters of TAQ DNA polymerase master mix. For agarose gel electrophoresis, $1 \mathrm{gm}$ of $0.8 \%$ agarose was weighed in the flask and to this 100 $\mathrm{ml}$ of Tris-acetate EDTA (TAE) was added. The solution was boiled to dissolve the agarose, then cooled down to $60^{\circ} \mathrm{C}$. 2 microliters of ethidium bromide was added to the solution and poured into the tray. The gel tray was allowed to cool at room temperature for 30 minutes which allowed for the solidification of the gel. Thereafter the PCR product was loaded on the gel and run at 100 volts. Then the results of the PCR was visualized under an ultraviolet illuminator.

\section{Statistical Analysis}

The results of all the cases were analyzed using Statistical Package of Social Science (SPSS) software, version 16 and Pearson's Chi square test was used to assess the statistical significance. ( $p<0.05$ was considered statistically significant).

\section{RESULTS}

In the present study 150 cases of OPMDS, 50 cases of OSCC and 50 healthy controls were included. The mean age of the cases was 44.5 years, however patients in age ranging from 20 to 60 years were included in the present study. Out of the 200 cases of the study population $70 \%$ were males and $30 \%$ females.

The results show that out of the 200 cases of OPMD's only $05(2.5 \%)$ cases showed positivity for HPV 16 and $0(0 \%)$ cases showed positivity for HPV 18. Only 1 out of 50 cases showed positivity for HPV-16 and 0 out of 50 cases 
showed positivity of HPV 18 in the ED cases. No cases of OLP showed positivity for HPV-16 and HPV 18.

Only 1 out of 50 cases of OSMF showed positivity for HPV-16, whereas HPV-18 was not found in any of the cases of OSMF. 03 out of 50 cases of OSCC was positive for OSCC whereas no cases showed positivity for HPV-18. However, HPV16 and 18 was completely missing in the control tissues. The results of the study are summarized in Table no. 1.

\section{DISCUSSION}

HPV in the pathogenesis of OPMDS and OSCC has been in talks and proposition since years yet the fact has not been well established. The present study showed the presence of HPV 16 virus genome in one case of epithelial dysplasia, one case of OSMF and three cases of oral squamous cell carcinoma. Although the results obtained in this study are statistically not significant but the association of HPV in oral potentially malignant disorders and oral malignancies could not be

Table 1. Results of the study.

\begin{tabular}{|l|l|l|l|l|}
\hline \multicolumn{1}{|c|}{ Groups } & $\begin{array}{c}\text { Total number of } \\
\text { Cases (N) }\end{array}$ & $\begin{array}{c}\text { Number of cases with } \\
\text { positivity of HPV-16 }\end{array}$ & $\begin{array}{c}\text { Number of cases with } \\
\text { positivity of HPV-18 }\end{array}$ & \multicolumn{1}{c|}{ p-Value } \\
\hline ED* & 50 & 01 & 00 & 0.3 \\
\hline OLP* & 50 & 00 & 00 & 0.54 \\
\hline OSMF* & 50 & 01 & 00 & 0.3 \\
\hline OSCC* & 50 & 03 & 00 & 0.21 \\
\hline Healthy Controls & 50 & 00 & 00 & 0.54 \\
\hline
\end{tabular}

*ED- Epithelial Dysplasia, OLP- Oral Lichen Planus, OSMF- Oral Submucous Fibrosis, OSCC- Oral Squamous Cell Carcinoma

ignored.

Among the 5 cases which shows positivity for HPV 16, 3 were males and 2 were females. Out of the five positive patients, buccal mucosa lesion was present in four of them. The details of the cases positive for HPV 16 are summarized in Table No. 2.

Cao J et al. ${ }^{17}$ in the year 2000 conducted a study to find out the prevalence of HPV in OSCC cases and reported a high prevalence of $72.5 \%$ in their cases. Similar results were obtained by the study conducted by Penhallow J et al. ${ }^{18}$ in the year 1998.

\begin{tabular}{|c|c|c|c|c|l|l|l|}
\hline \multicolumn{7}{|c|}{ Table 2. Summary of the cases which showed positivity for HPV 16.} \\
\hline Case & Sex* & Age & Habit** & Site*** & Presentation & $\begin{array}{r}\text { Provisional } \\
\text { Diagnosis }\end{array}$ & \multicolumn{1}{|c|}{ Final Diagnosis } \\
\hline 1 & M & 33 & S, ST & BM & White patch & Leukoplakia & Severe epithelial dysplasia \\
\hline 2 & M & 26 & ST & BM & White fibrous Bands & OSMF & OSMF \\
\hline 3 & F & 29 & ST & BM & $\begin{array}{l}\text { Ulcero-proliferative } \\
\text { lesion }\end{array}$ & Carcinoma & Moderately differentiated SCC \\
\hline 4 & M & 39 & S,A & BM & $\begin{array}{l}\text { White verruca- } \\
\text { papillary lesion }\end{array}$ & Squamous Papilloma & $\begin{array}{l}\text { Well-differentiated Squamous } \\
\text { Cell Carcinoma }\end{array}$ \\
\hline 5 & F & 31 & NH & T & Ulcer & Ulcer & $\begin{array}{l}\text { Well- differentiated Squamous } \\
\text { cell carcinoma }\end{array}$ \\
\hline
\end{tabular}

*M- Male, F- Female

**S- Smoking, ST- Smokeless Tobacco, A- Alcohol, NH- No Habits

*** BM- Buccal Mucosa, T- Tongue 
However, such high prevalence of HPV was not reported in our study population.

Cianfriglia $\mathrm{F}$ et al. ${ }^{19}$ in the year 2006 conducted a study to assess the presence of HPV in oral leukoplakia and found that $60 \%$ of the cases of his samples showed positivity for HPV and therefore the authors concluded that HPV is a supreme association between HPV and oral leukoplakia.

Sushma CN et al..$^{20}$ in the year 2017 conducted a study to find out the prevalence of HPV 16 in the oral leukoplakia cases using PCR and immunohistochemistry and found that $86 \%$ of the cases showed positivity for HPV 16 genome, however only $10 \%$ of the cases showed positivity with IHC.

Gomez-Armayones S et al. ${ }^{1}$ in the year 2019 conducted a study to find out the prevalence of HPV in premalignant lesions in a Spanish population and their results showed low prevalence of HPV in their sample population. The results obtained by them is in concordance with the present study.

Tyagi KK et al. ${ }^{6}$ in the year 2019 conducted a study in Nepal to find out the presence of HPV in OSCC cases and healthy controls and reported the presence of HPV in a small fraction of their OSCC cases, however they did not report any presence of HPV in health controls. Similar results were obtained in the present study where we reported the presence of HPV 16 and 18 in a fraction of OPMDS and OSCC and HPV was not reported in any of the healthy controls.

Tang KD et al. ${ }^{21}$ conducted a study in the year 2020 using the saliva samples and tissue biopsies to find out the prevalence of HPV 16 in OPMD and oral carcinoma and the authors reported that HPV is slightly more prevalent in oral carcinomas when compared with OPMD and their results are in concordance with the present study.
Kaewmaneenuan $\mathrm{N}$ et al. ${ }^{22}$ in the year 2021 conducted a study in Thailand to see the presence of HPV 16 and 18 in oral leukoplakia and lichen planus cases and found that HPV 16 and 18 were present in oral leukoplakia and lichen planus. However, they reported that HPV 18 was much more prevalent in their study population, when compared to HPV 16. In the present study, we could not find any cases of OPMD or oral cancer showing positivity for HPV 18.

Contrary to the previous studies, researches conducted by Young SK et al. $^{23}$ and Tsuchiya $\mathrm{H}$ et al. ${ }^{24}$ could not elucidate any association between HPV and oral precancerous lesions and oral cancer.

\section{CONCLUSIONS}

The association of HPV in the pathogenesis of oral, oropharyngeal cancers, and OPMD is not a new concept. However only limited number of studies are there in literature in this regard. In the present study we found only a limited number of cases showing positivity to HPV. The present study was conducted to provide an insight to the clinicians and researchers of Nepal about the role of HPV in the pathogenesis of OPMD and oral cancer. Further studies are required with increased sample size and extensive research is desirable in this field for the prevention and treatment of HPV related oral malignancies.

\section{Institutional Review Board Statement}

The study was conducted according to the guidelines of the Declaration of Helsinki, and approved by the Institutional Ethics Committee of M. B. Kedia Dental College Pvt. Ltd, Birgunj Nepal vide- 45/MBKDC/ADV/06/2018.

\section{Informed Consent Statement}

Being a retrospective study on archived content, informed consent does not apply here.

\section{Conflict of Interest}

The authors declare that they have no conflict of interest. 


\section{REFERENCES}

1) Gomez-Armayones $S$, Chimenos-Küstner E, Marí A, Tous S, Penin R, Clavero O, Quirós B, Pavon MA, Taberna M, Alemany L, Servitje O. Human papillomavirus in premalignant oral lesions: No evidence of association in a Spanish cohort. PloS one. 2019 Jan 16;14(1):e0210070.

2) Hirth JM, Chang M, Resto VA, Guo F, Berenson AB. Prevalence of oral human papillomavirus by vaccination status among young adults (18-30 years old). Vaccine. 2017; 35(27):3446-3451. https:// doi.org/ 10.1016/j.vaccine.2017.05.025 PMID: 28526331

3) Rao RS, Patil S, Ghosh S, Kumari K. Current aspects and future strategies in oral cancer research: A review. Journal of Medicine, Radiology, Pathology and Surgery. 2015 May 1;1(3):8-13.

4) Ghosh S, Rao RS, Upadhyay MK, Kumari K, Sanketh DS, Raj AT, Parveen S, Alhazmi YA, Jethlia A, Mushtaq S, Sarode S. Proliferative Verrucous Leukoplakia Revisited: A Retrospective Clinicopathological Study. Clinics and Practice. 2021 Jun;11(2):337-46.

5) de Martel C, Plummer M, Vignat J, Franceschi S. Worldwide burden of cancer attributable to HPV by site, country and HPV type. Int J Cancer. 2017; 141(4):664670. https://doi.org/10.1002/ijc.30716 PMID: 28369882

6) Tyagi KK, Pradhan M, Grewal RK, Sherchan P, Pasha KS. Assessment of Role of Human Papilloma Virus in Patients with Oral Squamous Cell Carcinoma. Journal of College of Medical SciencesNepal. 2019 Jun 30;15(2):125-7.
7) Raj AT, Patil S, Gupta AA, Rajkumar C, Awan $\mathrm{KH}$. Reviewing the role of human papillomavirus in oral cancer using the Bradford Hill criteria of causation. Disease-a-Month. 2019 Jun 1;65(6):15563.

8) Syrjänen S, Lodi G, von Bu“ltzingslo“wen I, Aliko A, Arduino P, Campisi G et al. Human papillomaviruses in oral carcinoma and oral potentially malignant disorders: A systematic review. Oral Dis. 2011; 17 (SUPPL. 1):58-72. https:// doi.org/10.1111/j.1601-0825.2011.01792.x PMID: 21382139

9) Ishibashi M, Kishino M, Sato S, Morii E, Ogawa Y, Aozasa K et al. The prevalence of human papillomavirus in oral premalignant lesions and squamous cell carcinoma in comparison to cervical lesions used as a positive control. Int J Clin Oncol. 2011; 16(6):646-653. https:// doi.org/10.1007/s10147-011-0236-0 PMID: 21528380

10) Epstein JB, Wan LS, Gorsky M, Zhang L. Oral lichen planus: progress in understanding its malignant potential and the implications for clinical management. Oral Surgery, Oral Med Oral Pathol Oral Radiol Endodontology. 2003; 96(1):32-37

11) Van der Waal I. Oral potentially malignant disorders: Is malignant transformation predictable and preventable? Med Oral Patol Oral Cir Bucal. 2014; 19(4):1-5.

12) Pol CA, Ghige SK, Gosavi SR. Role of human papilloma virus-16 in the pathogenesis of oral lichen planus-An immunohistochemical study. Int Dent J. 2015; 65(1):11-14. https://doi.org/10.1111/ idj.12125 PMID: 25256345 
13) Debanth S, Singh PA, Mehrotra R, Singh M, Gupta SC, Pandya S et al. Human papillomavirus infection and premalignant lesions of the oral cavity: A cross-sectional study in Allahabad, North India. Asia Pac J Clin Oncol. 2009; 5(2):111-118.

14) Campisi G, Giovannelli L, Aricò $P$, et al. HPV DNA in clinically different variants of oral leukoplakia and lichen planus. Oral Surgery, Oral Med Oral Pathol Oral Radiol Endodontology. 2004; 98(6):705711

15) Mattila R, Rautava J, Syrjänen S. Human papillomavirus in oral atrophic lichen planus lesions. Oral Oncol. 2012; 48(10):980-984. https://doi.org/10.1016/j. oraloncology.2012.04.009 PMID: 22658678

16) Sivapathasundharam B. Shafer's Textbook of Oral Pathology E-book. Elsevier Health Sciences; 2020 Jul 15.

17) Cao J, Zhang ZY, Patima, Zhang $Y X$, Chen WT. Human papillomavirus infection and p53 alteration in oral squamous cell carcinoma. Chin J Dent Res. 2000 Nov;3(3):44-9.

18) Penhallow J, Steingrimsdottir H, Elamin F, Warnakulasuriya S, Farzaneh F, Johnson N, Tavassoli M. p53 alterations and HPV infections are common in oral SCC: p53 gene mutations correlate with the absence of HPV 16-E6 DNA. Int J Oncol. 1998 Jan;12(1):59-68.

19) Cianfriglia F, Di Gregoreo DA, Cianfriglia $\mathrm{C}$, et al. Incidence of human papilloma virus in leukoplakia. Indications for a viral aetiology. J Exp Clin Cancer 2006; 25: 1

20) Sushma $C N$, Birur NP, Suresh A, Keerthi G, Sunny SP, Shubhasini AR, Shubha G, Kuriakose MA. Detection of HPV16 in tissues of oral leukoplakia by polymerase chain reaction and p16 immunohistochemistry: A prospective study. Translational Research in Oral Oncology. 2017 Aug 7;2:1-5.

21) Tang KD, Menezes L, Baeten K, Walsh LJ, Whitfield B, Batstone MD, Kenny L, Frazer IH, Scheper GC, Punyadeera C. Oral HPV16 prevalence in oral potentially malignant disorders and oral cavity cancers. Biomolecules. 2020 Feb;10(2):223.

22) Kaewmaneenuan N, Lekawanvijit $S$, Pongsiriwet S, Chatupos V, Iamaroon A. High Prevalence of Human Papillomavirus Type 18 in Oral Potentially Malignant Disorders in Thailand. Asian Pacific Journal of Cancer Prevention. 2021 Jun 1;22(6):1875-81.

23) Young SK, Min KW. In situ DNA hybridization analysis of oral papillomas, leukoplakias, and carcinomas for human papillomavirus. Oral surgery, oral medicine, oral pathology. 1991 Jun 1;71(6):726-9.

24) Tsuchiya $H$, Tomita $Y$, Shirasawa $H$, Tanzawa H, Sato K, Simizu B. Detection of human papillomavirus in head and neck tumors with DNA hybridization and immunohistochemical analysis. Oral surgery, oral medicine, oral pathology. 1991 Jun 1;71(6):721-5.

Citation: Ghosh S, Wazir S, Shah R, Upadhyay M, Gupta R, Singh H. Detection of Human Papilloma Virus in Oral Potentially Malignant Disorders and Oral Squamous Cell Carcinoma. JCMS Nepal. 2021 ; 17(3); 279-85. 